RESENHA 

Nuntius Antiquus, Belo Horizonte, v. 11, n. 2, p. 155-159, 2015

\section{Elegias de Sexto Propércio, por Guilherme Gontijo Flores}

\section{The Elegias de Sexto Propércio, by Guilherme Gontijo Flores}

PROPÉRCIO, Sexto. Elegias de Sexto Propércio. Organização, tradução, introdução e notas de Guilherme Gontijo Flores. Belo Horizonte: Autêntica Editora, 2014, 527 p. (ISBN: 978-85-8217-395-4)

Leandro Dorval Cardoso

Faculdade de Ciências e Letras da UNESP de Araraquara leandrodorval@gmail.com

Recebido em 23 de setembro de 2015

Aprovado em 15 de outubro de 2015

Doze anos após a primeira tradução completa de Sexto Propércio ao português (PROPÉRCIO, 2002), a Autêntica Editora publica o empenho de Guilherme Gontijo Flores (poeta, tradutor e professor de Latim na UFPR) em traduzir um dos grandes elegíacos romanos. Bilíngue, a edição apresenta um Propércio livre do vício filológico da academia, em versos portugueses que se prestam a leitores de um modo geral e a estudantes de Literatura Clássica. Com dois textos introdutórios seguidos pelos quatro livros das elegias, por um conjunto de notas e um posfácio, o volume, fruto de dissertação defendida por Flores (2008), configura-se como uma introdução bastante completa a Propércio.

Parte desse trabalho de tradução recai, porém, na escolha de uma edição crítica a ser seguida, pois os problemas da transmissão de 
textos afetam bastante a Propércio: as discordâncias entre seus editores são inúmeras, desde lições específicas até versos ora atribuídos a um poema, ora a outro. Seguindo a edição de Paolo Fedeli (PROPÉRCIO, 2002), o tradutor declara (PROPÉRCIO, 2014, p. 25) alinhar-se à postura dos falsos conservadores, mas considerando edições com propostas mais renovadoras, como as de Goold (1990) e Heyworth (2007). Com informações bastante relevantes, se a Introdução e a seção sobre o texto não se detêm nas minúcias de cada questão que abordam, cumprem seu papel destacando pontos relevantes da obra. Assim, o leitor não chegará aos poemas completamente desarmado.

Agora, algumas considerações sobre a tradução propriamente dita. A elegia romana é caracterizada, dentre outras coisas, por uma estrutura métrica específica: os dísticos elegíacos, compostos por um hexâmetro e um pentâmetro datílicos. Assim, a despeito das diferenças entre os versos, há certa constância rítmica, visto que são datílicos. Para manter essa estrutura o máximo possível, Flores optou por uma tendência da tradução dos clássicos gregos e latinos ao português, traduzindo cada dístico por um dodecassílabo e um decassílabo - João Ângelo Oliva Neto, por exemplo, empregou essa forma em seu Livro de Catulo (CATULO, 1996) e no Falo no jardim (OLIVA NETO, 2006). Assim, Flores aproxima Propércio de poetas latinos já traduzidos ao português e mantém uma característica da elegia romana, escolhendo versos de medidas diferentes, mas de ritmos semelhantes, já que os dodecassílabos seguem os padrões de acentuação na $6^{\mathrm{a}}$ e $12^{\mathrm{a}}$ sílabas poéticas e na $4^{\mathrm{a}}$, $8^{\mathrm{a}}$ e $12^{\mathrm{a}}$, e os decassílabos são heroicos, ou sáficos. Pode-se perceber, também, a manutenção das ideias circunscritas a cada dístico, evitando o seu cavalgamento entre dois deles (Prop., 2.3.9-12):

nec me tam facies, quamuis sit candida, cepit

(lilia non domina sunt magis alba mea;

ut Maeotica nix minio si certet Hibero,

utque rosae puro lacte natant folia).

Não me prendeu seu rosto, embora seja branco,

(lírios não são mais alvos que seus braços:

como a neve Meótica no mínio Ibérico,

ou pétalas de rosa sobre o leite) 
Nesses versos, podemos ver um esforço por contemplar, também, a sonoridade dos poemas de Propércio. Note-se o verso $11-\bar{u} t$ Maēotiča $a$ nīx minnı̄o sì cērtět Hĭbērō - em que as consoantes nasais concentramse em um único bloco, fazendo pesado o verso assim como o é a neve, para o que também colaboram as sílabas longas; pode-se ver ainda uma aproximação, no que toca à identidade da vogal inicial e final, entre minı̌o e Hǐberrō, palavras que compõem um sintagma, mas estão separadas pelo si certet. Na tradução, lemos "como a neve Meótica no mínio Ibérico", que mantém e incrementa o peso nasal do verso e o eco vocálico entre mínio e Ibérico. No verso 21 do mesmo poema, é o [k] que se repete em quase todas a palavras: et sua cum antiquae committit scripta Corinnae, traduzido "por confrontar seus cantos contra os de Corina". A exploração melopaica em português segue, na tradução, princípios utilizados por Propércio e, embora às vezes uma imagem sonora em latim não tenha uma símile em seu correspondente na tradução, Flores não se furtou a explorar essas imagens, sem transformá-las, contudo, em afetação.

Sobre a linguagem empregada, soa, no Propércio traduzido, aquele sermo familiaris característico das elegias romanas, que não deixa de elevar-se quando o texto latino se eleva. Em 2.15: illa meos somno lapsos patefecit ocellos/ ore suo et dixit: "Sicine, lente, iaces?" (v. 7-8), traduzido por "com seus lábios abriu meus olhinhos de sono/ e me disse: 'Ah molenga, estás dormindo?"', a doçura do diminutivo latino ocellos é retomada por "olhinhos", e a intimidade dos amantes resplandece no "molenga", ótima escolha para verter lente nesse contexto. Em 1.3, há uma passagem (v. 1-6) em que o vocabulário equilibra-se com os símiles escolhidos para promover Cíntia ao mesmo patamar das figuras evocadas, o que logrou-se manter com as formas adjetivas "Cnóssia" ("de Cnosso"), "Cefeia" ("filha de Cefeu") e "Edônide" ("das Edônides"), dando ao trecho um tom quase épico, embora sua sintaxe pareça menos épica que a do original (Prop., 1.3.1-6):

qualis Thesea iacuit cedente carina

languida desertis Cnosia litoribus; qualis et accubuit primo Cepheia somno

libera iam duris cotibus Andromede;

nec minus assiduis Edonis fessa choreis

qualis in herboso concidit Apidamo. 
Tal como, ao se afastar do barco de Teseu, prostrou-se a Cnóssia lânguida na praia; tal como enfim adormeceu Cefeia Andrômeda ao se livrar dos ásperos rochedos; ou como a Edônide exaurida pelas danças

que desfalece no relvoso Apídano:

Há, deve-se dizer, questões pontuais que dizem bastante sobre a tradução. Âs vezes, pela adequação aos parâmetros métricos, percebemse mudanças nas imagens propercianas, como no verso 10 do já citado poema 2.3: lilia non domina sunt magis alba mea, em que a alvura de Cíntia, a domina mea, relaciona-se àquela dos lírios ("os lírios não são mais alvos que a minha senhora"). Na tradução, lemos "lírios não são mais alvos que seus braços". A substituição de mea domina por "seus braços" não afeta, porém, a comparação - se a senhora é alva, alvos são seus braços - nem a relação criada entre o eu e sua amada: domina pode ser traduzido por "senhora", mas também por "amante", sentido relevante nesse contexto. Com "braços", é certo, muda-se o foco da imagem, mas não a referência, já que eles podem ser símbolo de domínio e de carinho - é com eles que se abraça em enlace afetivo -, mas também de aprisionamento. Além disso, os braços já foram, na literatura brasileira, motivadores da libido, como em "Uns braços", conto de Machado de Assis.

Outro exemplo pode ser colhido no poema 1.5, em que o eu alerta outra persona sobre os perigos da paixão (v. 13-4): A! mea contemptus quotiens ad limina curres, / cum tibi singultu fortia uerba cadent; na tradução: "Desprezado virás (e muito!) ao meu umbral,/ ao cair soluçante tua soberba". As diferenças são novamente explicáveis pelas exigências do padrão métrico adotado, mas há uma diferença maior entre fortia uerba e "soberba" que aquela entre domina mea e "seus braços", visto que fortia, embora possa referir-se à soberba, destaca, nesse contexto metalinguístico, mais o vigor e a dureza das palavras que sua altivez. $\mathrm{O}$ mais importante, contudo, é a queda causada pelo enfraquecimento, seja o das palavras vigorosas ou da soberba.

Em todos os casos nos quais há tais mudanças, porém, não há o que se perca, pois as escolhas feitas ainda operam dentro de possibilidades da elegia erótica romana. Assim, pode-se dizer que a tradução, correta e primorosa, soará interessante ao leitor bilíngue, que poderá, mais que ler 
um Propércio em português, descobrir caminhos pelos quais a tradução se deu, acrescendo sentidos aos poemas traduzidos; àquele incapaz de acompanhar o texto latino, ela mostrará um Propércio pouco diferente do Propércio em latim.

Segue-se aos poemas um longo posfácio, de autoria do tradutor, no qual a discussão sobre tradução ganha contornos precisos. Nele, Flores defende sua tarefa ante um arcabouço teórico/crítico em que Haroldo de Campos, Ezra Pound e Meschonnic, dentre outros, possuem papéis importantes, discutindo a tradução em termos de diversão, "a produção de prazer e de diferença em todos os campos possíveis" (PROPÉRCIO, 2014, p. 442), uma busca "que se assuma como produtora de diferença e veja nisso sua única possibilidade" (PROPÉRCIO, 2014, p. 468). Destaque-se, por fim, a boa qualidade crítica do volume, repleto de notas e textos de grande importância para os leitores.

\section{Referências}

CATULO. O livro de Catulo. Trad., introdução e comentários de João Angelo Oliva Neto. São Paulo: EDUSP, 1996.

FLORES, G. G. A diversão tradutória: uma tradução das elegias de Sexto Propércio. 2008. 151 f. Dissertação (Mestre em Estudos Literários) Faculdade de Letras, Universidade Federal de Minas Gerais, 2008.

GOOLD, G. P. Propertius - Elegies. Cambridge, Mass.: Harvard University Press, 1990.

HEYWORTH, S. J. Sexti Properti elegos. Critico apparatu instruxit et edidit S. J. Heyworth. Oxford: Oxford University Press, 2007.

OLIVA NETO, J.-A. Falo no Jardim: priapeia grega, priapeia latina. Trad., estudos, notas e iconografia de João Ângelo Oliva Neto. Cotia - SP/ Campinas: Ateliê Editorial/Editora da Unicamp, 2006.

PROPÉRCIO. Elegias. Edição de Paolo Fedeli, trad. Aires A. Nascimento, Maria Cristina Pimentel, Paulo F. Alberto, J. A. Segurado e Campos. Assisi/Lisboa: Accademia Properziana del Subasio/Centro de Estudos Clássicos, 2002. 